\title{
APPLICATION OF OSCILLOSCOPE TECHNOLOGY IN THE EARLY 21ST CENTURY: A SYSTEMATIC LITERATURE REVIEW
}

\author{
Theophilus Ezra Nugroho Pandin ${ }^{1}$ \\ ${ }^{1}$ Faculty of Engineering, Widya Mandala Catholic University Surabaya \\ Email: electreng.theophilus.e.20@ukwms.ac.id
}

\begin{abstract}
Background: An oscilloscope is a basic tool for measuring electrical quantities, as well as studying all types of waveforms. Generally, measurement of a quantity is regarding peak voltage, frequency, phase difference, pulse width, delay time, etc. However, what about the oscilloscope technology that existed in the early the 21st-century? Purpose: Aim of this study is to identify and analyze the application and use of current oscilloscopes in the early $21 \mathrm{st}-$ century. Method: The research methodology used is qualitative research with a systematic literature review by taking journals from 2019-2020 on the IEEE, IOP, Science Direct, ArXiv, and Measurement Science Review journal databases. Results: The results obtained are a batch of 12 articles showing the application and use of oscilloscope technology at the beginning of the 21 st century. Conclusion: The conclusions applied to the application of oscilloscope technology in the early 21 st-century are centered on the field of education in the measurement of physical quantities and the use of measurement technology which has high efficiency and low cost.
\end{abstract}

Keywords: oscilloscope; 21st-century technology; measuring instrument technology

\section{INTRODUCTION}

An oscilloscope is a basic tool used for measuring electrical quantities, as well as studying all types of waveforms such as sinusoidal waves, square waves, triangular waves, sawtooth waves, ramp waves, complex waves, etc [1]. Quantity measurements are carried out such as peak voltage, frequency, phase difference, pulse width, delay time, rise time, and fall time. The invention of the oscilloscope stems from the discovery of the Cathode Ray Tube by Ferdinand Braun until his subsequent discoveries, namely the Dual Beam Oscilloscope by AC Cossor (around 1930), the Triggered Sweep Oscilloscope (1946), and the Direct View Bistable Storage Tube (1963) by Howard Vollum and Jack Murdock, as well as Digital Storage Oscilloscope (DSO) by Walter LeCroy (1963). Since these various discoveries, the conventional oscilloscope that is currently available has been achieved [2][3][4], [5]. However, what about the development of oscilloscope technology in the early 21 st-century.

Based on the description above, the research question in this article is "How is the application of oscilloscope technology used in the early 21st-century?", "How are the technological developments created in the early 21 st-century oscilloscope?". So that, the purpose of this study is to identify and analyze the application and use of current oscilloscope technology in the early 21 st-century. Therefore, these findings can be used as 
a reference for further research regarding the application and use of oscilloscope-related technology by future researchers, so that the same research is not necessary.

\section{METHODS}

This study uses a qualitative methodology with a systematic literature review. The research step of the systematic literature review was adapted from Xiao and Watson's guide [6]. The article material is taken from reputable international journals related to electricity and the latest technology in oscilloscopes, including the Institute of Electrical and Electronics Engineers (IEEE), Institute of Physics (IOP), Measurement Science Review, Science Direct from Elsevier, and non- peer-review journal ArXiv. The articles taken for this research material were published in the range 2019 - 2021. The keyword used in finding the article was "oscilloscope". Based on the keyword search, 76 articles were found on the IEEE database, 749 articles on Science Direct, 376 articles on the IOP, 1 article on Measurement Science Review, and 9 non-peer-reviewed articles on the journal ArXiv. Furthermore, the filtering of article data is carried out by applying the title which has the vocabulary "oscilloscope" in it. So that the total data obtained from the database is 35 articles. Then filtering and reductions were carried out based on the time the article material was published in the period $2019-2021$, as well as the relevance of the topics raised. So, that found 12 articles that match the criteria and relevance. After the article is found, the article material is extracted based on the grouping of data according to the title, name of the author of the article, year of publication, topic or research context, research objectives, research flow, research methodology, research results, conclusions from research, the technology used in oscilloscopes, application of oscilloscope technology, and the contribution of research findings to technological developments in the early 21 st century. Grouping and analyzing research data is assisted using the ATLAS.ti software.

\section{Article Search Strategy}

Articles were obtained by searching on the database of IEEE, IOP, Measurement Science Review, non-peer review journal ArXiv using the "oscilloscope" keyword in this study.

\section{Inclusion Criteria}

The criteria for journal article used are determined based on the following: 1) Research titles discuss oscilloscope technology, 2) The abstract is clear and complete, and 3) The articles taken were published from 2019 until 2021.4) the relevance of the article on oscilloscope technology

\section{Exclusion Criteria}

The criteria for journal article used are determined based on the following: 1) Research titles are not discussed oscilloscope technology, 2) The abstract is not clear and complete, and 3) The articles published are not from 2019 until 2021. 4) the relevance of the article does not discuss further about oscilloscope technology

Figure 1. Flow chart of this study 


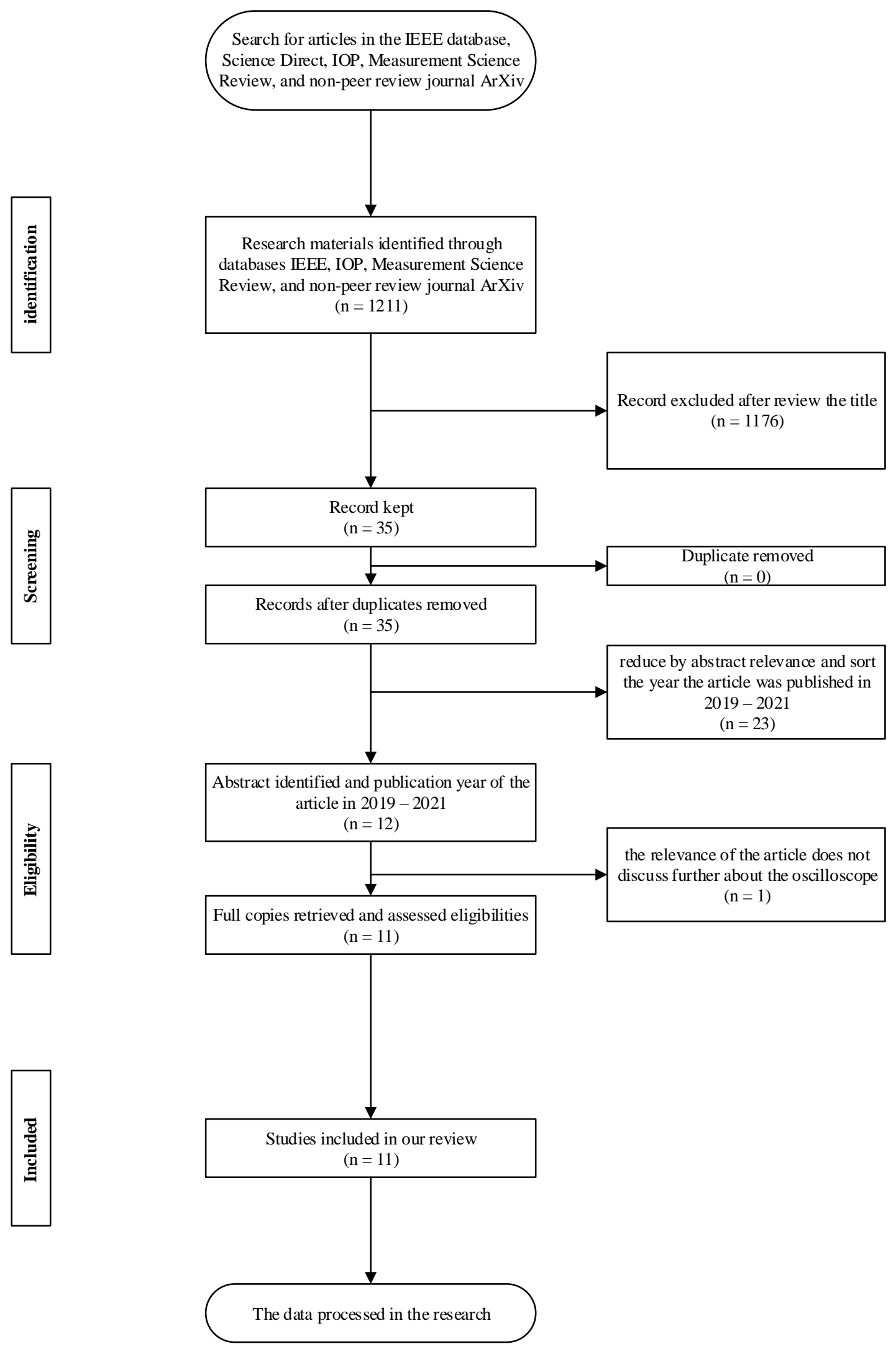

\section{RESULT}

Table 1. Distribution of the application, novelty and contribution of oscilloscope technology in the early 21 st-century 


\begin{tabular}{|c|c|c|c|}
\hline Researcher, year & Oscilloscope technology & $\begin{array}{c}\text { application of } \\
\text { oscilloscope technology }\end{array}$ & $\begin{array}{c}\text { Contributions of the } \\
\text { oscilloscope technology } \\
\text { in the early 21st- } \\
\text { century }\end{array}$ \\
\hline Ramos and Devers [7] & $\begin{array}{l}\text { Portable oscilloscope } \\
\text { technology using the } \\
\text { Oscium iMSO-204 on } \\
\text { the iPad device. }\end{array}$ & $\begin{array}{l}\text { Oscium iMSO-204 based } \\
\text { portable oscilloscope and } \\
\text { the iPad or tablet as a } \\
\text { practical and user- } \\
\text { friendly teaching } \\
\text { method. }\end{array}$ & $\begin{array}{l}\text { The existence of portable } \\
\text { oscilloscope technology } \\
\text { based on Oscium iMSO- } \\
204 \text { and iPad or tablet } \\
\text { makes it easier for non- } \\
\text { engineering and non- } \\
\text { science students to be } \\
\text { able to use the functions } \\
\text { of an oscilloscope that is } \\
\text { more user-friendly. }\end{array}$ \\
\hline Fontana et al., 2020 [8] & $\begin{array}{lr}\text { Digilent } & \text { Analog } \\
\text { Discovery } 2 & \text { (AD2) dan } \\
\text { Red Pitaya } & \text { STEMLab } \\
125-14 & \end{array}$ & $\begin{array}{l}\text { The use of a digital } \\
\text { oscilloscope as signal } \\
\text { digitizer for detectors in } \\
\text { nuclear physics. }\end{array}$ & $\begin{array}{l}\text { A comparison of two } \\
\text { digital oscilloscopes with } \\
\text { the CAEN DT5725 and } \\
\text { DT5751 desktop } \\
\text { digitizer provides the } \\
\text { results of the } \\
\text { oscilloscope as a detector } \\
\text { digitization technology } \\
\text { in nuclear physics } \\
\text { experiments which is } \\
\text { more affordable. }\end{array}$ \\
\hline $\begin{array}{c}\text { Cossu, Sturniolo } \\
\text { Ciaramella, } 2020 \text { [9] }\end{array}$ & $\begin{array}{l}\text { Complementary Metal- } \\
\text { Oxide Semiconductor } \\
\text { (CMOS) as Real-Time } \\
\text { Oscilloscope (RTO) }\end{array}$ & $\begin{array}{l}\text { Its application is to } \\
\text { measure oscilloscope } \\
\text { parameters in general } \\
\text { such as frequency, noise, } \\
\text { Signal to Noise Ratio, } \\
\text { Total Harmonic } \\
\text { Distortion (THD) }\end{array}$ & $\begin{array}{l}\text { A CMOS camera } \\
\text { modeled as an RTO for } \\
\text { optical signal } \\
\text { measurement can be used } \\
\text { in high bandwidth OCC. }\end{array}$ \\
\hline $\begin{array}{c}\text { Singh and Kaur, } 2019 \\
{[10]}\end{array}$ & $\begin{array}{l}\text { Digital Storage } \\
\text { Oscilloscope (DSO) }\end{array}$ & $\begin{array}{l}\text { Application of Digital } \\
\text { Storage Oscilloscope } \\
\text { (DSO) in describing or } \\
\text { visualizing } \\
\text { electromagnetic } \\
\text { induction output, which } \\
\text { is the occurrence of } \\
\text { induced emf in a } \\
\text { solenoid. }\end{array}$ & $\begin{array}{l}\text { Digital Storage } \\
\text { Oscilloscope (DSO) can } \\
\text { be used as a teaching aid } \\
\text { to demonstrate the } \\
\text { concept } \\
\text { electromagnetic } \\
\text { induction. }\end{array}$ \\
\hline $\begin{array}{l}\text { Tankeliun, Zaytsev, and } \\
\text { Urbanavicius, } 2019 \text { [11] }\end{array}$ & $\begin{array}{l}\text { PicoScope- } 9301 \\
\text { sampling oscilloscope } \\
\text { with a bandwidth of } 25 \\
\mathrm{GHz}\end{array}$ & $\begin{array}{l}\text { Hybrid Time-Based } \\
\text { (HTB) for oscilloscopes } \\
\text { makes it possible to } \\
\text { reduce the uncertainty in } \\
\text { determining the time } \\
\text { position of the sample in } \\
\text { the horizontal channel of } \\
\text { the sampling } \\
\text { oscilloscope. }\end{array}$ & $\begin{array}{l}\text { Hybrid Time-Based } \\
\text { devices can reduce } \\
\text { sampling oscilloscope } \\
\text { jitter several times and } \\
\text { aberrations with a } \\
\text { constant time distortion } \\
\text { component are } \\
\text { practically absent in this } \\
\text { device. }\end{array}$ \\
\hline
\end{tabular}




\begin{tabular}{|c|c|c|c|}
\hline Dbicki et al., 2019 [12] & $\begin{array}{l}\text { The oscilloscope device } \\
\text { can acquire signals for up } \\
\text { to } 32 \text { detectors at the } \\
\text { same time, sampling rate } \\
\text { of } 10 \mathrm{MHz}, 10 \text { bit ADC, } \\
\text { microcontroller, FPGA, } \\
\text { and micro-processor with } \\
\text { Linux }\end{array}$ & $\begin{array}{l}\text { Multi-channel signal } \\
\text { acquisition and analysis } \\
\text { system for the } \\
\text { registration of large } \\
\text { numbers of neutrons, } \\
\text { neutron detectors, in } \\
\text { particular with the } \\
\text { simultaneous } \\
\text { measurement of a } \\
\text { coherent signal of a } \\
\text { number of neutrons. }\end{array}$ & $\begin{array}{l}\text { The data acquisition } \\
\text { system on the latest } \\
\text { measurements allows } \\
\text { recording of the entire } \\
\text { waveform without } \\
\text { (nearly) lag time. }\end{array}$ \\
\hline Zhao et al., 2019 [13] & Terahertz oscilloscope & $\begin{array}{l}\text { Application of Terahertz } \\
\text { Oscilloscope is used to } \\
\text { record time information } \\
\text { from an ultrashort } \\
\text { electron beam by } \\
\text { injecting laser-driven } \\
\text { THz pulses of circular } \\
\text { polarization into a } \\
\text { dielectric tube. }\end{array}$ & $\begin{array}{l}\text { The use of the Terahertz } \\
\text { Oscilloscope has } \\
\text { achieved a resolution of } \\
24 \mathrm{fs} \text { in measuring the } \\
\text { temporal profile of the } \\
\text { beam and an accuracy of } \\
3 \mathrm{fs} \text { in determining the } \\
\text { arrival time of the beam } \\
\text { with pulses. }\end{array}$ \\
\hline Sakti et al., 2019 [14] & $\begin{array}{l}\text { Gain and phase detector } \\
\text { by AD8302, and digital } \\
\text { storage oscilloscope by } \\
\text { Picoscope 5244B. }\end{array}$ & $\begin{array}{l}\text { Comparison of gain and } \\
\text { phase detector circuits } \\
\text { coupled with Quartz } \\
\text { Crystal Microbalance } \\
\text { with Digital Storage } \\
\text { Oscilloscope }\end{array}$ & $\begin{array}{l}\text { Digital Storage } \\
\text { Oscilloscope, as a signal } \\
\text { measurement instrument, } \\
\text { DSO provides more } \\
\text { accurate results than } \\
\text { phase gain integrated } \\
\text { circuit detectors. DSO } \\
\text { requires pre-processing } \\
\text { signal using the most } \\
\text { suitable sinusoidal model } \\
\text { to get a clear signal to } \\
\text { calculate }\end{array}$ \\
\hline Cho et al., 2019 [15] & $\begin{array}{l}\text { Measurement method for } \\
\text { the response of a } \\
\text { commercial real-time } \\
\text { digital oscilloscope }\end{array}$ & $\begin{array}{l}\text { The application is carried } \\
\text { out by characterizing the } \\
\text { frequency response of } \\
\text { each ADC in a } \\
\text { commercial RTDO using } \\
\text { calibrated pulses. }\end{array}$ & $\begin{array}{l}\text { A description of the } \\
\text { traceable measurement } \\
\text { method for the frequency } \\
\text { response of a commercial } \\
\text { real-time digital } \\
\text { oscilloscope (RTDO) is } \\
\text { applied. }\end{array}$ \\
\hline
\end{tabular}

The number of bits is increased by 0.5 bits at some frequency points in the $1 \mathrm{GHz}$ band, making waveform capture more precise. In essence the new QIADC architecture increases the vertical resolution of the

The technology applied is measurement and sampling to measure the performance of the QIADC system
The new architecture in parallel ADC is used by (QIADC, to obtain more bits of resolution means of Quantization
Gao et al., 2019 [16] oscilloscope. 


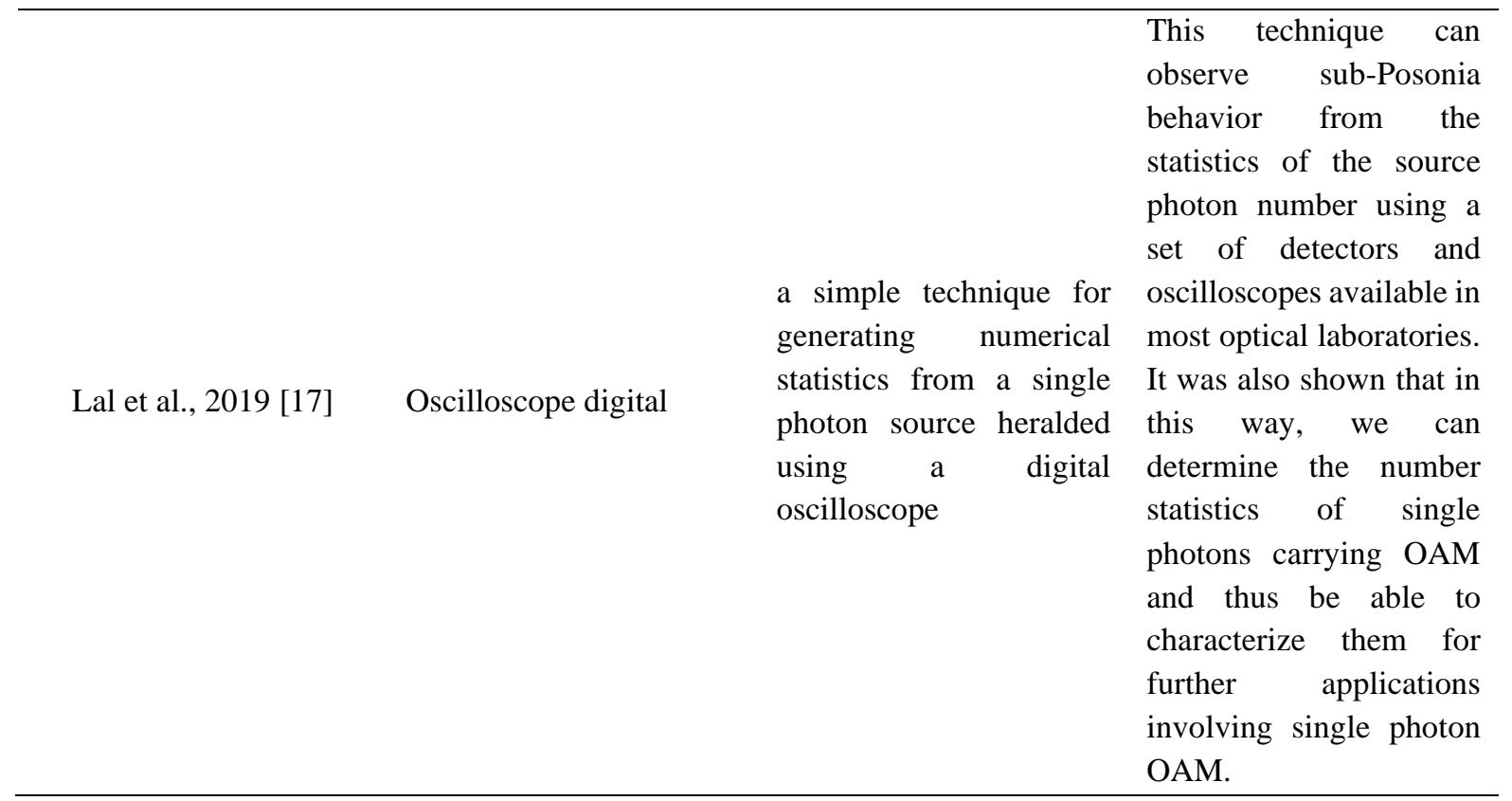

\section{DISCUSSION}

In the 21st century, the oscilloscope has undergone various developments and changes. Based on the articles that have been extracted and filtered from the existing categories, the application of oscilloscope technology is carried out in several fields, namely education, and teaching, detection technology in nuclear physics, CMOS camera sensors as real-time oscilloscopes in capturing optical signals, use of hybrid time-based systems. data acquisition, terahertz oscilloscope, impedance measurement on Quartz Crystal Microbalance, Quantization Interleaving Analog-Digital Converter, and sub-Poissonian Statistics.

\section{Educational}

In the field of education and teaching, more adequate facilities are implemented to fulfill the function of oscilloscopes that are more friendly to use for students who are more lay with oscilloscopes, especially for non-engineering and non-science students, such as students studying medicine, nursing, biology, pharmacy, etc.

The iPads, tablets, and even other Android devices can be applied to teach the use of an oscilloscope provided that the device has an input $3.5 \mathrm{~mm}$ audio jack. Of course, this device is also supported by other accessories, namely the Oscium iMSO-204 as a tool that converts the signal from a circuit being tested. The teaching carried out in the article is applied to constant time measurement in RC and LC circuits. The survey results prove that using an iPad or tablet with the help of the Oscium iMSO-204 accessory is more userfriendly than conventional oscilloscopes, because it is more practical, with fewer buttons and switches. The appearance and use of an iPad or tablet that is often encountered in students' daily lives is one of the factors[7].

In the next article, written by I. Singh and B. Kaur, we present the use of a Digital Storage Oscilloscope to visualize the output of electromagnetic induction in experiments. 
The Digital Storage Oscilloscope (DSO) can be used as a teaching aid in the classroom to demonstrate the concept of electromagnetic induction. The students have gone through rigorous conceptual and mathematical analysis of the induced electromotive force (emf), but there has always been a curiosity among students about how the induced emf varies as the magnet approaches or moves away from a stationary solenoid. With a modern version of the experimental setup, students can actually visualize the phenomenon of electromagnetic induction on an oscilloscope screen and they themselves can verify Lenz's law. This article aims to present an effort to improve experimental skills and increase students' confidence in interpreting experimental observations. With this article, students get an idea of how the induced emf in a solenoid varies with the speed of the magnet, the verification of Lenz's law, and the function of various components in an experimental setting through visualizations obtained on DSO in each component in the circuit [10].

\section{Detection in Nuclear Physics}

In the technology for detection in nuclear physics, the digital oscilloscope acts as a substitute for desktop digitizing devices. Comparisons were made to determine the digitization capabilities of the four devices, namely the CAEN DT5725 and DT 5751 desktop digitizers with the Digilent Analog Discovery 2 (AD2) digital oscilloscope and The Red Pitaya STEMLab 125 - 14. The desktop digitizer is a desktop module that requires a computer to control the acquisition. The desktop digitizer requires a $+12 \mathrm{~V}$ power sources. Specifications are as follows:

- DT5725: has 8 input channels, 14 bit ADC, a sampling rate of $250 \mathrm{MS} / \mathrm{s}$ (Mega Samples per second), and a bandwidth of $125 \mathrm{MHz}$.

- DT5751: has 2 to 4 input channels, 10 bit ADC, a sampling rate of 1 to 2 GS / s (Giga Samples per second), and a bandwidth of $500 \mathrm{MHz}$.

Both have MCX connectors on the input line making this impractical because they don't offer the commonly used coaxial connectors namely BNC or LEMO 00. Both also have an input impedance of $50 \Omega$ with a selectable input dynamic range from $0 \mathrm{~V}$ to $0.5 \mathrm{~V}$ or $0 \mathrm{~V}$ to $2 \mathrm{~V}$. With CAEN's proprietary DPP-PSD firmware, input channels are independent with trigger standard firmware between all channels.

Meanwhile, the digital oscilloscope has the following specifications:

- Digilent Analog Discovery 2 (AD2): USB digital oscilloscope with 2 input channels, 14 bit ADC, $100 \mathrm{MS}$ / s sampling rate (Mega Samples per second), $30 \mathrm{MHz}$ bandwidth, $1 \mathrm{M} \Omega$ impedance with dynamic range $\pm 25 \mathrm{~V}$. The inputs are on the pin strip connector and the BNC connector. It has a high input impedance so a $50 \Omega$ terminator must be added to the input.

- Red Pitaya STEMLab 125 - 14: digital oscilloscope in embedded Linux computer with 2 input channels, 14 bit ADC, 125 MS / s sampling rate (Mega Samples per second), $50 \mathrm{MHz}$ bandwidth, $1 \mathrm{M} \Omega$ input impedance with dynamic range $\pm 1 \mathrm{~V}$ or $\pm 20 \mathrm{~V}$. Has remote control via ethernet connection, but requires an external power supply of $5 \mathrm{~V}$. With the SMA connector input line, a BNC adapter with a $50 \Omega$ terminator is installed 
Based on these specifications, the advantage of the AD2 oscilloscope is that it is more compact than the CAEN desktop digitizer and does not require an external power supply. Meanwhile, the advantages of Red Pitaya STEMLab 125 - 14 are in terms of data acquisition and storage control, as well as remote control capabilities.

Comparative testing was carried out with the ABCD data acquisition system to compare the performance of two CAEN desktop digitizers (DT5725 and DT5751) with two lowcost oscilloscopes (Digilent Analog Discovery 2 and Red Pitaya STEMLab 125-14). Comparisons were carried out using several classical measurements of nuclear physics experiments: spectroscopy, pulse shape discrimination (PSD), and time. This process is carried out with the same analysis algorithm on the application of the resulting data. The results are summarized in the table below, sourced from the article reviewed [8]:

Table 2. Comparison of the two oscilloscopes with the two desktop digitizers

\begin{tabular}{|c|c|c|c|c|c|c|c|c|c|c|}
\hline & \multirow[t]{2}{*}{ Connection } & \multirow[t]{2}{*}{ Ch. } & \multirow{2}{*}{$\begin{array}{c}\text { ADC res. } \\
\text { [bit] }\end{array}$} & \multirow{2}{*}{$\begin{array}{c}\text { Sampl. rate } \\
{[\mathrm{MS} / \mathrm{s}]}\end{array}$} & \multirow[t]{2}{*}{ Dyn. range } & \multirow{2}{*}{$\begin{array}{l}\text { Max. acq. rate } \\
{[\text { evt/(s ch)] }}\end{array}$} & \multicolumn{2}{|c|}{ Energy resolution [\%] } & \multirow{2}{*}{$\begin{array}{c}\text { PSD FOM } \\
\text { EJ301 }\end{array}$} & \multirow{2}{*}{$\begin{array}{c}\text { ToF FWHM } \\
\text { [ns] }\end{array}$} \\
\hline & & & & & & & $\mathrm{NaI}(\mathrm{Tl})$ & $\mathrm{LaBr}_{3}(\mathrm{Ce})$ & & \\
\hline \multicolumn{11}{|l|}{ CAEN Digitizers } \\
\hline DT5725 & USB, optical & 8 & 14 & 250 & $0.5 \mathrm{Vpp}$ or $2 \mathrm{Vpp}$ & $10^{6}$ & 7.578 & 3.288 & 2.17 & 0.898 \\
\hline DT5751 & USB, optical & 4 & 10 & 1000 & $0.5 \mathrm{Vpp}$ or $2 \mathrm{Vpp}$ & $10^{6}$ & 7.934 & 3.416 & 2.50 & 0.748 \\
\hline \multicolumn{11}{|l|}{ Oscilloscopes } \\
\hline STEMLab 125-14 & Ethernet, USB & 2 & 14 & 125 & $\pm 1 \mathrm{~V}$ or $\pm 20 \mathrm{~V}$ & 4000 & 7.726 & 3.376 & 1.91 & 1.34 \\
\hline Analog Discovery 2 & USB & 2 & 14 & 100 & $\pm 25 \mathrm{~V}$ & 100 & 9.81 & 3.916 & 1.61 & 1.19 \\
\hline
\end{tabular}

Based on the spectroscopic comparison the DT5725 has the best performance, a factor of the combination of a sampling frequency of $250 \mathrm{MS} / \mathrm{s}, 14 \mathrm{bit} \mathrm{ADC}$, and a small dynamic range (0.5 Vpp or $2 \mathrm{Vpp}$ ). STEMLab $125-14$ is slightly better than DT5751. Then, AD2 has the worst performance overall, considering the wide range that 14 bits have to cover. Pulse shape discrimination (PSD) comparisons gave similar results to spectroscopic comparisons. CAEN's desktop digitizer has the best performance, but in this comparison, the DT5751 is superior to the DT5725.

Finally, for the time comparison, the DT5751 has the best performance with the subnanosecond resolution, although the DT5725 has sub-nanoseconds, the sampling frequency is slower and results in results. Whereas AD2 has a better time resolution than Pitaya STEMLab 125-14. This is strange considering the fact that AD2's sampling frequency is slower than Pitaya STEMLab 125-14.

Based on these results, in terms of technology for detectors in nuclear physics, this lowcost oscilloscope can serve as a valid alternative to specialized digitization. Acquisition performances were all comparable. In addition, two digital oscilloscopes offer advanced options in embedded firmware that were not evaluated in the article (such as complex trigger logic, onboard coincidence determination, or onboard waveform analysis)[8].

\section{CMOS Camera Sensor}

In the following article, written by G. Cossu, A. Sturniolo, and E. Ciaramella, a quantitative method is introduced to evaluate a CMOS camera sensor modeled as an RTO for optical signals. The tool can be used for high bandwidth OCC applications. This article proposes an effective method for obtaining camera sampling rates, then also introduces the equivalent parameters used to characterize RTOs, and they measure them in CMOS 
cameras. The article also describes the effect of JPEG conversion on signal integrity. This detailed characterization is a new tool that allows maximizing camera performance in OCC applications.

Measurements are taken on the actual camera of a commercial smartphone, as a function of the intensity of the received signal (controlled attenuation in front of the camera) and all the parameters the camera can control (exposure time and ISO value). Further investigation may be possible to have full control over the optical recorder, such as characterization of saturation, bloom effect, and complete analysis of the RAW image format [9].

\section{Hybrid Time-Based}

In the next article, we describe a new technique for restoring the equivalent time axis in modern sampling oscilloscopes, called hybrid time base (HTB) incoherent sampling on oscilloscopes. This sample time position recovery technique is more accurate than conventional time bases and has a smaller jitter error. In the case of this article, coherence means that the frequency of the signal under test and the frequency of the strobe pulse are in a certain ratio.

The idea of coherent sampling itself is well known, but in practice, it works effectively only at sufficiently high strobe pulse frequencies (typically tens of megahertz) and at signal testing frequencies below well over hundreds of megahertz.

The main problem encountered is the long-term frequency stability of the strobe pulse and the signal under test. In the proposed technique a coherent sampling mode is used to support optimal operating conditions for another way to recover the equivalent time base, which is called "trigonometry". It should be noted that the proposed method can be applied using only one additional sampling circuit, whereas a similar solution requires a minimum of two sampling circuits and a phase switch at 90 degrees.

Another disadvantage of the proposed HTB technique is that the temporal positioning of the sample directly depends on the oscilloscope vertical channel metrology parameters such as noise, temperature drift, and nonlinear distortion. Therefore, this article is intended to offer a way to reduce noise and vertical channel nonlinearity in the near future.

In addition to the above, the reference oscillation used in the HTB device must have low noise and not have extraneous harmonics. This is difficult to achieve in practice. Therefore, it is necessary to troubleshoot the strict requirements for reference oscillations. It is known that sampling oscilloscopes operate more efficiently at low frequencies: the frequency of the strobe pulses is on the order of hundreds of kilohertz (at low frequencies there is less interference on the vertical channel and a wider sampler bandwidth). The prototype made by demonstrating the possibility of functioning at a strobe pulse frequency of $1 \mathrm{MHz}$ and less.

Preliminary experimental studies of the proposed HTB device have shown that jitter can be reduced by more than 2.0 times. Experiments also show that the deviation component of the recovery error from the equivalent time axis is practically absent in the HTB device when the signal-under-test and reference harmonic waveform are phase-locked.

The most problematic in this study is the recovery of the time position by the "adjacent point" technique interpolation. In the future, in order to overcome this disadvantage, it will 
be focused on such research to ensure better frequency stability of the coherent sampling mode [11].

\section{Data Acquisition System}

The new measurement data acquisition system implemented in this article, will allow recording of the entire waveform without (nearly) downtime. The large number of measuring channels allows flexible selection of the configuration and type of detector used in the measurement. The differential input of the electrical signal from the detector allows avoiding interference in signal transmission from the detector to the ADC. Each measuring line has the ability to control two independent external power supplies that can be used to power the detector. The trigger parameters of individual data acquisition channels can be set independently in a very flexible way. Thanks to the programmable gate system (FPGA), easy upgrades of the system are possible. The undoubted advantage is the use of a microprocessor system with its own operating system, thanks to which it is possible to carry out measurements without an additional PC. This is especially important in locations where access to electricity can be very limited (eg in mines). The low electricity demand allows the use of battery powered power sources, which is especially important in mines where the power supply can be very unstable and interfere with measurements [12].

\section{Terahertz Oscilloscope}

In this article they demonstrate a useful new and practical method for recording relativistic electron beam timing information. In this experiment, a resolution of $24 \mathrm{fs}$ was achieved in the measurement of the temporal profile of the beam and an accuracy of $3 \mathrm{fs}$ in determining the arrival time of the beam with a THz pulse having a field strength of about $150 \mathrm{kV} / \mathrm{cm}$ and a dielectric tube with $\mathrm{D}=0.87 \mathrm{~mm}$. As the defection mode impedance scales as D 3 and $\mathrm{THz}$ pulses with fields exceeding $1 \mathrm{MV} / \mathrm{cm}$ have been reached), the resolution of the $\mathrm{THz}$ oscilloscope can potentially be extended to sub-femtoseconds with stronger $\mathrm{THz}$ pulses and smaller aperture dielectric tubes. It should be noted that the temporal resolution in these measurements is inversely proportional to the square root of the electron energy, so this $\mathrm{THz}$ oscilloscope can also be applied directly to characterize the electron beams with higher energies. Furthermore, this $\mathrm{THz}$ oscilloscope can be directly used to temporarily increase the resolution of Ultrafast Electron Diffraction.

For example, the diffracted beam downstream of the sample can be swept with a $\mathrm{THz}$ oscilloscope, forming a ring pattern for operating Ultrafast Electron Diffraction in film mode. In this configuration, the temporal resolution in Ultrafast Electron Diffraction is no longer limited by the electron bunch length and time jitter, but rather by the temporal resolution of the $\mathrm{THz}$ oscilloscope, which allows one to achieve femtosecond temporal resolution with a picosecond electron beam. It is hoped that this $\mathrm{THz}$ oscilloscope has wide application in many research fields [13].

\section{Quartz Crystal Microbalance}

This article describes the use of Quartz Crystal Microbalance (QCM) sensors which have developed rapidly in various fields, especially in the study of chemistry and biology. Since the first introduction of this device in 1959, researchers have developed many basic 
aspects and applications of QCM. The focus is not only on the structure of the sensor, surface or layer but also through improving its interface to obtain more sophisticated measurements and to explore the possibilities for obtaining more information from measurements. Measurement of the response of the Quartz Crystal microscale can be carried out using frequency measurements, signal dissipation, as well as impedance measurements. Among many methods, electrical impedance is one of the preferred analysis. This method provides rich information. Each method has its own advantages and disadvantages. The impedance of the QCM determines the behavior of the QCM operating under the senses. Impedance measurements can lead us to investigate materials, such as complex shear modulus, viscosity, and loading effects caused by coatings on QCM surfaces. However, the need for relatively expensive measuring instruments may be unavoidable. The complexity in stating is one of the main reasons.

In impedance measurement, a sinusoidal signal (input signal) is injected into the circuit containing the element under test. The signal before the circuit is the input signal and the circuit signal is the output signal. Impedance calculation is done by comparing the input signal and output signal by considering the circuit configuration. In this experiment, they used a simple voltage divider circuit with known resistive elements. Impedance and phase values are calculated based on signal measurements using a phase gain integrated circuit detector and digital storage oscilloscope.

Phase gain integrated circuit detectors are widely used for magnitude and phase measurement. In many applications, these tools have been used to obtain useful information for research to explain more phenomena. For example, it can be used for superheterodyne microwave interferometers and for tissue bioimpedance spectra. Based on the device, the magnitude and phase are generated from the analog AC voltage signal. As a result, the device also has the potential to measure the QCM impedance with some modified circuitry before it is detected by the device.

The phase gain integrated circuit detector takes two signals as input and produces two DC output signals that are proportional to the ratio of the magnitude and phase difference of the two signals.

The detector usually detects inputs within a certain frequency range. For example, the AD8302 (Analog Devices, USA) can only detect and process RF/IF input. The device may be made to detect low frequency signals if some modification is made to the input circuit. The resonant frequency of a typical QCM sensor ranges from $5 \mathrm{MHz}$ to $20 \mathrm{MHz}$. This range closely matches the detected range of AD8302.

DSO is now widely available. With advances in microelectronic technology, DSOs with sampling rates up to $\mathrm{GHz}$ and data storage up to Gigabytes are available. There are two main advantages to using a DSO as an instrument for signal measurement. First, the measured data can be stored automatically on a personal computer which provides an easy way for further processing.

Second, DSOs are usually commercialized with the ability to measure AC input across multiple channels, usually in two or four channels. Therefore, using recorded signals measured at the same time, gain and phase shift can be calculated.

In this experiment, we compare two methods of measuring the electrical impedance of the QCM sensor around the series resonant frequency. The AC signal source is a direct digital 
signal generator, AD-9910. This experiment shows that by using the most suitable processing stage, it can eliminate the instability of the signal generator.

Direct comparisons have been made between a Digital Storage Oscilloscope (DSO) and a phase gain integrated circuit detector have been investigated. Gain phase detectors require averaging data for each measurement to reduce signal source variation. DSO provides more accurate results than phase gain integrated circuit detectors. DSO requires pre-processing signals using the most suitable sinusoidal model to get a clear signal to calculate. However, the DSO requires relatively complex processing to obtain the impedance and phase yield, and the phase gain integrated circuit detector simplifies the measurement process [14].

\section{Real-Time Oscilloscope}

In this paper, a characterization method for the frequency response of each ADC in a commercial RTDO is described using calibrated pulses. In this article, the frequency response covariance was obtained by analyzing the uncertainty of the RTDO measurement, impedance mismatch correction, pulse standard, and reproducibility. The standard deviation is easily obtained by taking the square root of the diagonal matrix of the covariance matrix. The $95 \%$ confidence interval has an amplitude uncertainty of about 0.2 $\mathrm{dB}$ and a phase uncertainty of about $3^{\circ}$. This article also compares the proposed method with the sine sweep method and ensures that they agree well with the uncertainty [15].

\section{Quantization Interleaving Analog Digital Converter}

In this article, a parallel acquisition architecture is proposed to increase the vertical resolution for ultra-fast applications. By interleaved sampling in the vertical axis, more bits of resolution are obtained in the acquisition system.

In this article, we introduce quantization theory from a statistical perspective to build the basic theory of QIADC. In addition, a precise improvement analysis has been proposed and proven by a statistical quantization sample model for the first time. Furthermore, a high-resolution oscilloscope prototype has been designed based on a dual channel Quantization Interleaving structure. Experiments were conducted to demonstrate the real effectiveness of QIADC from three aspects, namely baseline test, dynamic test, and arbitrary waveform test. Compared with the traditional method, the experimental results show a higher dynamic range and ENOB with the QIADC technique. Except for being applied to instruments integrated with acquisition systems, the proposed technique also provides a new perspective in the design of high-resolution integrated circuits [16].

\section{Sub-Poissonian Statistics}

A conventional quantum optical experiment to determine the non-classical statistical behavior of a single photon source involves a time-to-digital converter along with associated post-processing. Here, we introduce a simple technique for generating numerical statistics from a heralded single-photon source using a digital oscilloscope. Signals and idlers in the SPDC output are detected and registered in the oscilloscope. From the recorded data, a time series corresponding to chance detection and a corresponding distribution of numbers is obtained. In this way, one can observe the sub-Posonia behavior of the source 
photon-number statistics using the set of detectors and oscilloscopes available in most optical laboratories. We also show that in this way we can determine the number statistics of single photons carrying OAM and thus be able to characterize them for further applications involving single-photon OAM [17].

\section{CONCLUSIONS}

In the end, it can be concluded that the application of oscilloscope technology in the 21 st century is growing rapidly in several fields as described in the discussion, namely in the fields of education and teaching and technological developments in the oscilloscope parts. In some of these discussions, it can be categorized that the technologies developed and of interest to researchers for the last 3 years are nuclear physics measurement technology, digital storage oscilloscope (DSO) technology, ADC technology on oscilloscopes, and real-time digital oscilloscope technology, data acquisition systems, timebased hybrid, using Quartz Crystal Microbalance camera sensors, Sub-Poissonian Statistics.

The application of oscilloscope technology in the 21 st century is generally developed to produce tools that have full features and low cost. The use of the oscilloscope is also for measuring other quantities that rely on sinusoidal waves.

\section{REFERENCES}

[1] D. A. Bell, "David A Bell-Electronic Instrumentation and Measurements-Prentice-Hall of India (2003).pdf." hal. 451, 1997.

[2] P. Russer, "Ferdinand Braun - A pioneer in wireless technology and electronics," Eur. Microw. Week 2009, EuMW 2009 Sci. Prog. Qual. Radiofreq. Conf. Proc. - 39th Eur. Microw. Conf. EuMC 2009, no. November 2009, hal. 547-554, 2009, doi: 10.1109/EUMC.2009.5296324.

[3] J. M. D. Pereira, "The History and Technology An overview of its primary characteristics," hal. 27-35, 2006.

[4] H. Anderson, “A Simplified Direct-Viewing Bistable Storage Tube," IEEE Trans. Electron Devices, no. 12, hal. 159-160, 1967, doi: 10.1109/T-ED.1967.16118.

[5] E. Notes, "What is an Oscilloscope: basics \& fundamentals," electronicsnotes. https://www.electronics-notes.com/articles/test-methods/oscilloscope/scope-basics.php (diakses Mei 20, 2021).

[6] Y. Xiao dan M. Watson, "Guidance on Conducting a Systematic Literature Review," J. Plan. Educ. Res., vol. 39, no. 1, hal. 93-112, 2019, doi: 10.1177/0739456X17723971.

[7] R. Ramos dan C. Devers, "The iPad as a virtual oscilloscope for measuring time constants in RC and LR circuits," Phys. Educ., vol. 55, no. 2, 2020, doi: 10.1088/13616552/ab606b.

[8] C. L. Fontana, N. Tuccori, F. E. Pino, M. Lunardon, L. Stevanato, dan S. Moretto, "Performance comparison between signal digitizers and low-cost digital oscilloscopes: Spectroscopic, pulse shape discrimination and timing capabilities for nuclear detectors," arXiv, 2020, doi: 10.1088/1748-0221/15/06/P06020. 
[9] G. Cossu, A. Sturniolo, dan E. Ciaramella, "Modelization and characterization of a CMOS camera as an optical real-time oscilloscope," IEEE Photonics J., vol. 12, no. 6, 2020, doi: 10.1109/JPHOT.2020.3032951.

[10] I. Singh dan B. Kaur, "Using a digital storage oscilloscope to visualise the induced EMF of a magnet passing through a solenoid," Phys. Educ., vol. 54, no. 4, 2019, doi: 10.1088/1361-6552/ab1350.

[11] T. Tankeliun, O. Zaytsev, dan V. Urbanavicius, "Hybrid Time-Base Device for Coherent Sampling Oscilloscope," Meas. Sci. Rev., vol. 19, no. 3, hal. 93-100, 2019, doi: 10.2478/msr-2019-0015.

[12] Z. Dbicki et al., "Fast multi channel acquisition system without dead time capable to measure oscilloscope-like signals.," J. Phys. Conf. Ser., vol. 1181, no. 1, 2019, doi: 10.1088/1742-6596/1181/1/012072.

[13] L. Zhao et al., "Terahertz oscilloscope for recording time information of ultrashort electron beams," Phys. Rev. Lett., vol. 122, no. 14, hal. 1-6, 2019, doi: 10.1103/PhysRevLett.122.144801.

[14] S. P. Sakti, E. R. N. Akbar, D. D. Kamasi, dan A. Naba, "Impedance Measurement of the Quartz Crystal Microbalance using Phase Gain Detector and Digital Storage Oscilloscope," IOP Conf. Ser. Mater. Sci. Eng., vol. 546, no. 4, 2019, doi: 10.1088/1757-899X/546/4/042040.

[15] C. Cho, H. Koo, J. Y. Kwon, dan J. G. Lee, "Uncertainty Analysis for Characterization of a Commercial Real-Time Oscilloscope Using a Calibrated Pulse Standard," IEEE Access, vol. 7, hal. 159724-159730, 2019, doi: 10.1109/ACCESS.2019.2950683.

[16] J. Gao et al., "Theory of Quantization-Interleaving ADC and Its Application in HighResolution Oscilloscope," IEEE Access, vol. 7, hal. 156722-156732, 2019, doi: 10.1109/ACCESS.2019.2949701.

[17] N. Lal, B. Shajilal, A. Anwar, C. Perumangatt, dan R. P. Singh, "Observing subPoissonian statistics of twisted single photons using oscilloscope," Rev. Sci. Instrum., vol. 90, 2019, doi: 10.1063/1.5109544. 